\title{
A lithiophilic 3D conductive skeleton for high performance Li metal battery
}

Jun-ru Wang, Meng-meng Wang, Xiao-dong He, Shuo Wang, Jie-min Dong, Fei Chen, Aqsa Yasmin and Chun-hua Chen*

CAS Key Laboratory of Materials for Energy Conversions, Department of Materials

Science and Engineering \& Collaborative Innovation Center of Suzhou Nano Science and Technology, University of Science and Technology of China, Anhui Hefei 230026, China

${ }^{*}$ Corresponding author: cchchen@ustc.edu.cn (C.-H. Chen) 


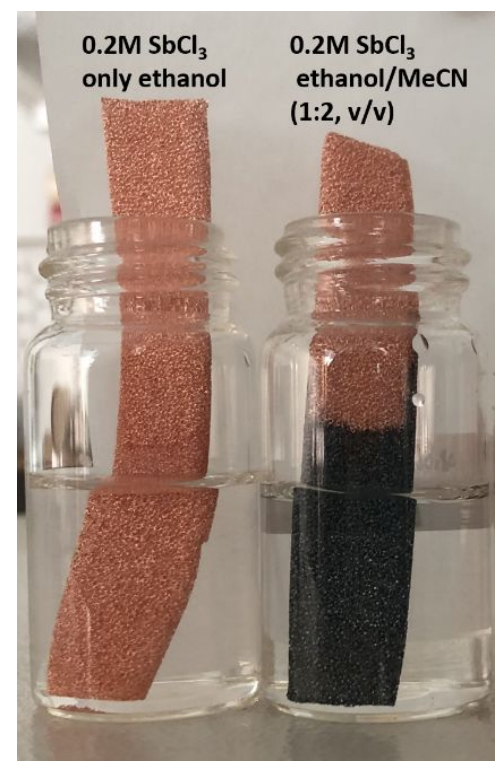

Figure S1. Photograph showing different phenomenon of $\mathrm{Cu}$ foam immersed in different mixed solution: only ethanol containing $0.2 \mathrm{M} \mathrm{SbCl}_{3}$ (left), ethanol/MeCN (1:2, $\mathrm{v} / \mathrm{v}$ ) containing $0.2 \mathrm{M} \mathrm{SbCl}_{3}$ (right).
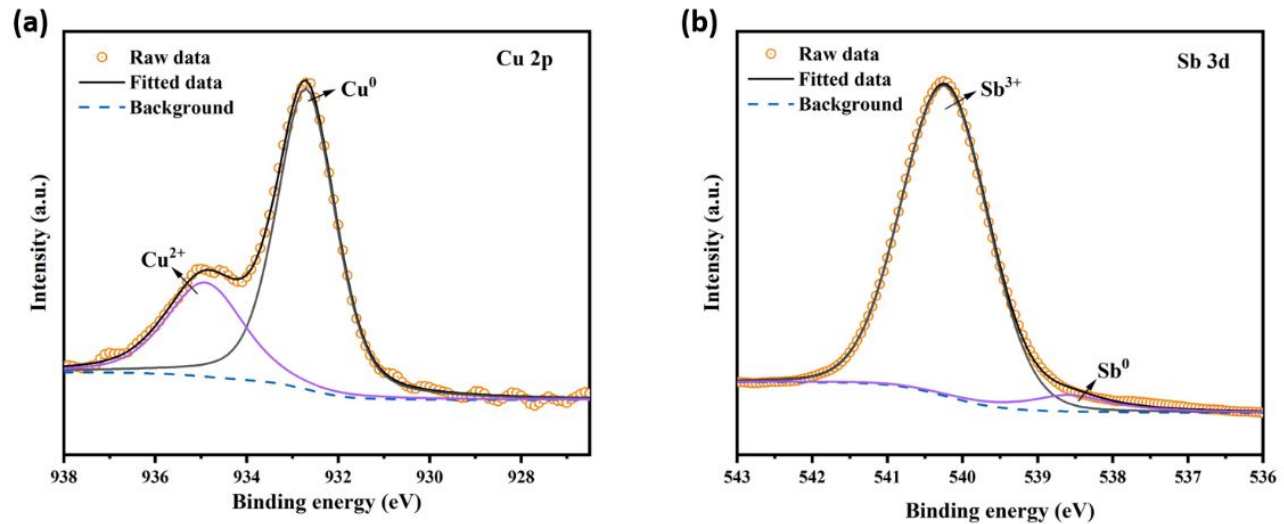

Figure S2. High-resolution XPS spectra of Cu(f)@Sb. 


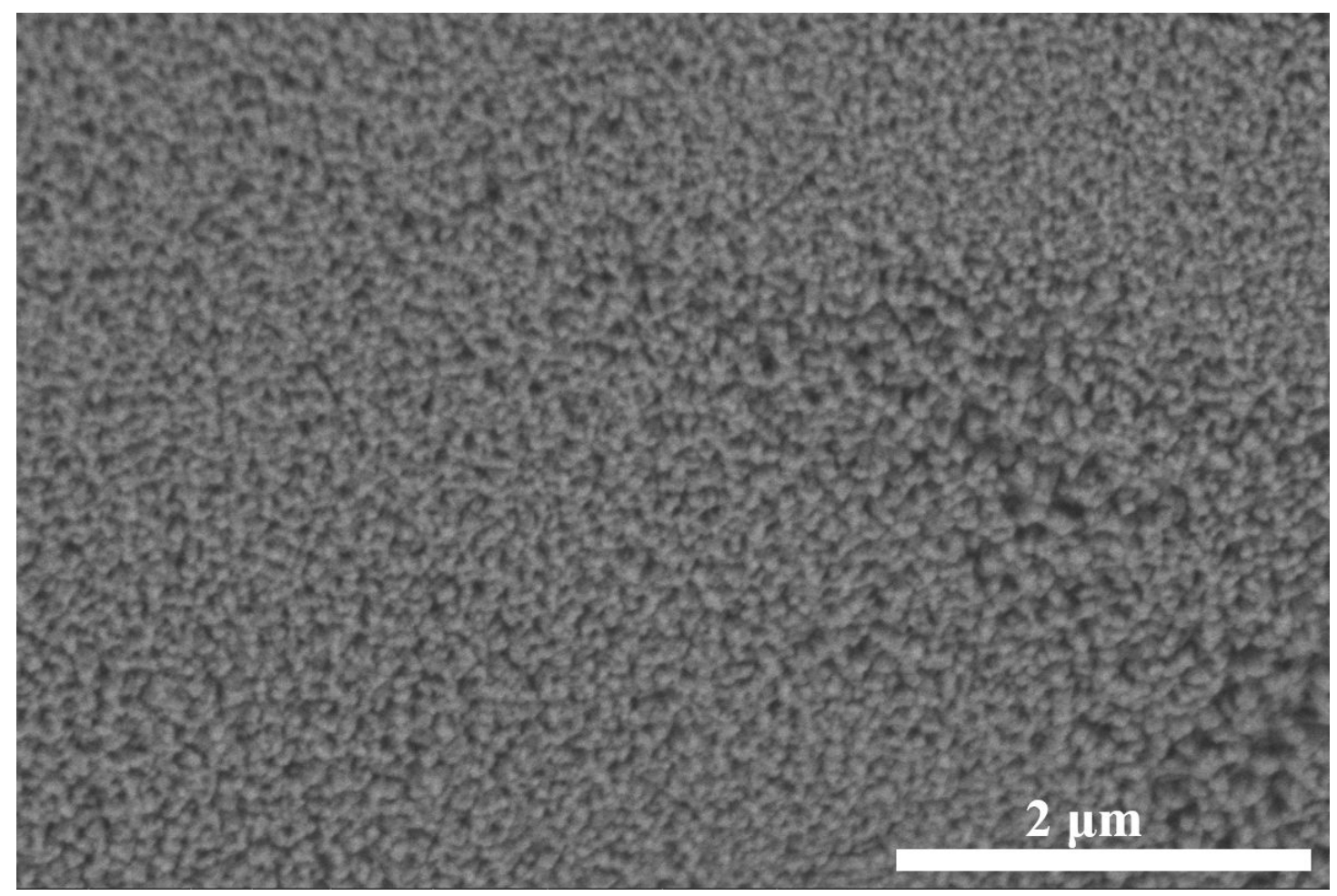

Figure S3. High resolution SEM images of $\mathrm{Cu}(\mathrm{f}) @ \mathrm{Sb}$.
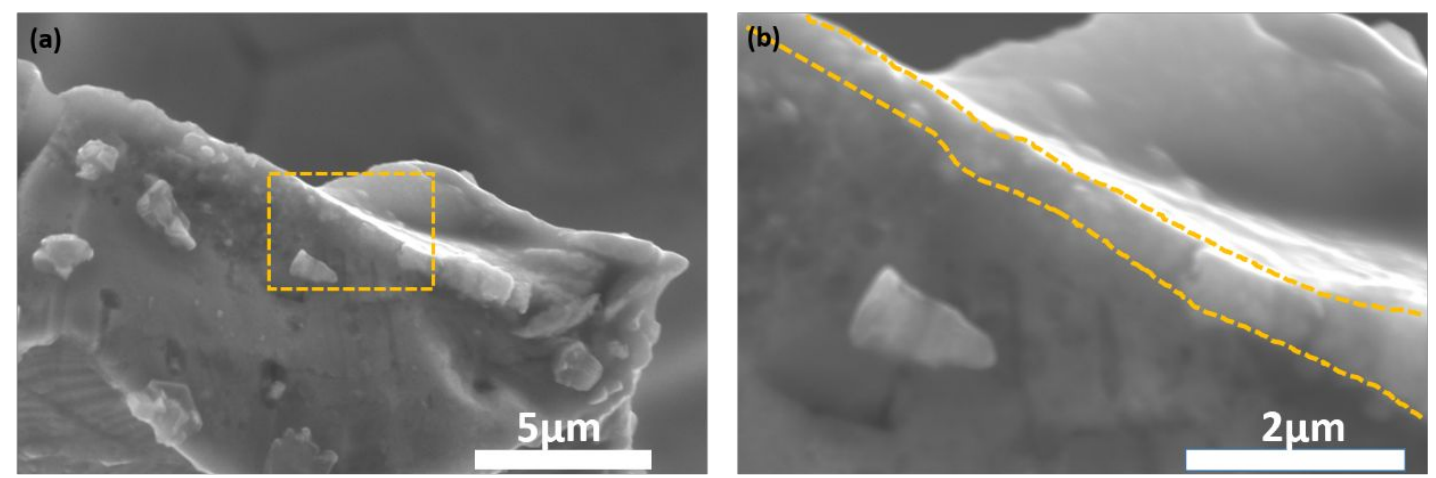

Figure S4 (a) Cross-sectional SEM images of $\mathrm{Cu}(\mathrm{f}) @ \mathrm{Sb}$ and $(\mathrm{b})$ the magnification of the selected area. 


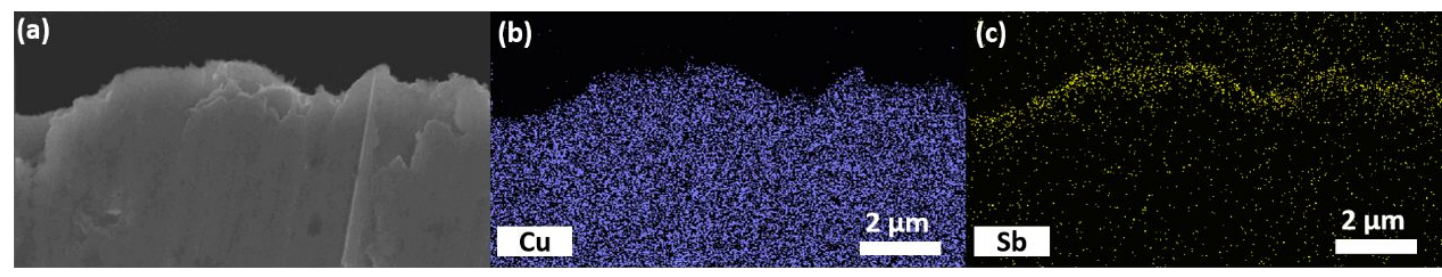

Figure S5 The EDS results of Cross-sectional Cu(f)@Sb.

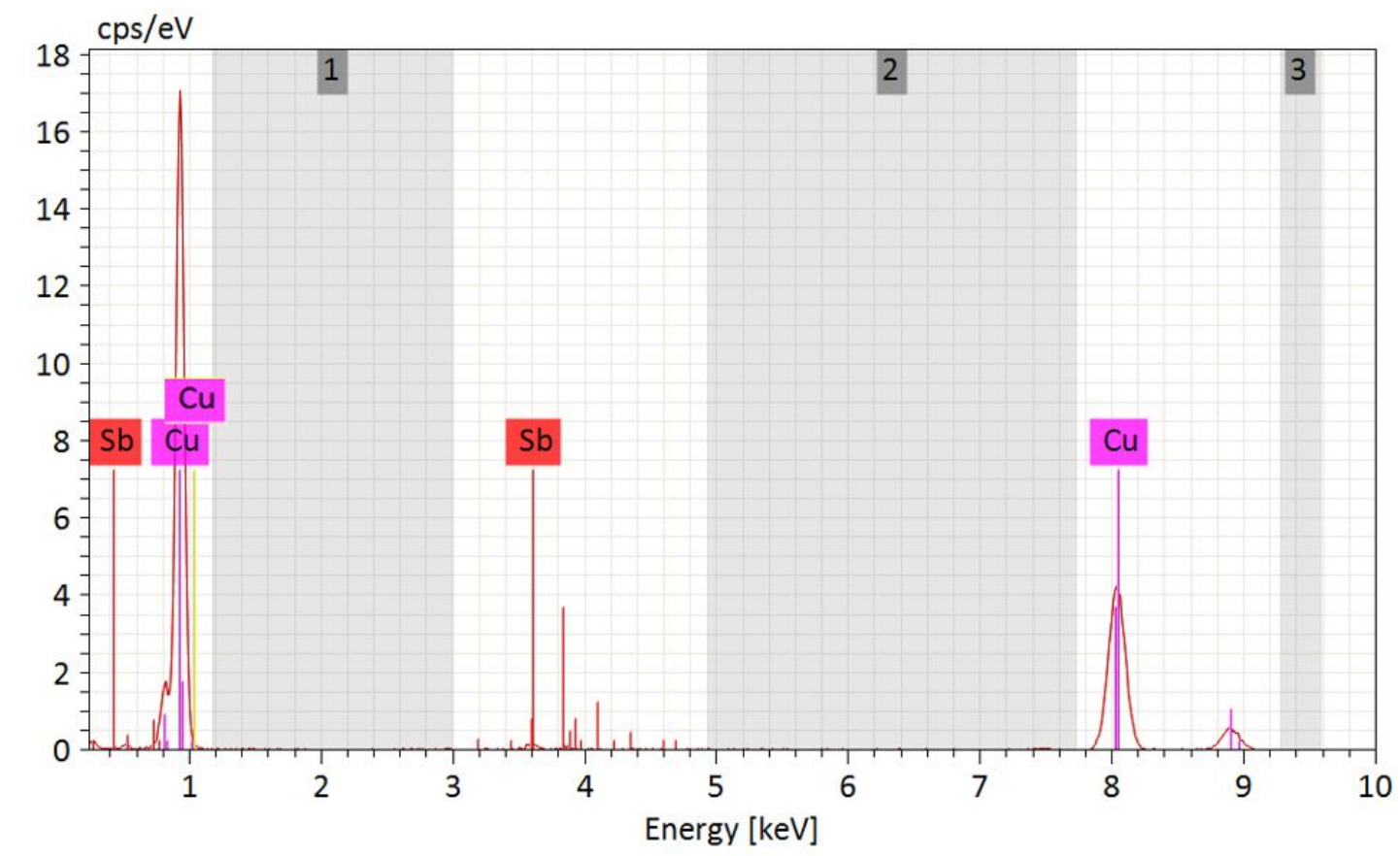

\section{Acquisition}

\begin{tabular}{|c|c|c|c|c|c|c|c|}
\hline Element & At. No. & Netto & $\begin{array}{c}\text { Mass } \\
{[\%]}\end{array}$ & $\begin{array}{c}\text { Mass Norm. } \\
{[\%]}\end{array}$ & $\begin{array}{c}\text { Atom } \\
{[\%]}\end{array}$ & $\begin{array}{l}\text { abs. error [\%] } \\
\text { (1 sigma) }\end{array}$ & $\begin{array}{c}\text { rel. error [\%] } \\
\text { (1 sigma) }\end{array}$ \\
\hline $\mathrm{Cu}$ & 29 & 44799 & 86.92 & 97.71 & 98.79 & 2.39 & 2.75 \\
\hline \multirow[t]{2}{*}{$\mathrm{Sb}$} & 51 & 2063 & 2.03 & 2.29 & 1.21 & 0.10 & 5.10 \\
\hline & & Sum & 88.96 & 100.00 & 100.00 & & \\
\hline
\end{tabular}

Figure S6 The EDS results of $\mathrm{Cu}(\mathrm{f}) @ \mathrm{Sb}$. 


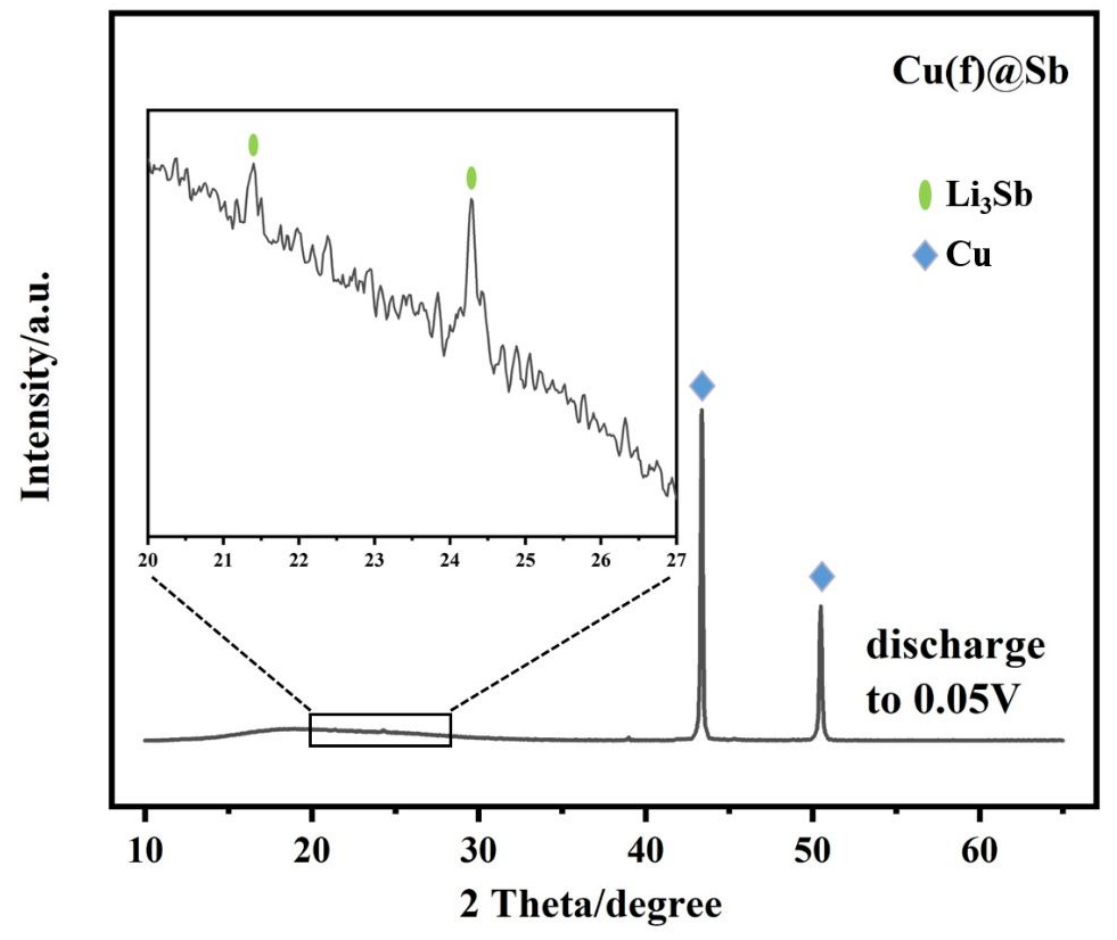

Figure S7 Ex-situ XRD pattern of $\mathrm{Cu}(\mathrm{f}) @ \mathrm{Sb}$ discharged to $0.05 \mathrm{~V}$. 

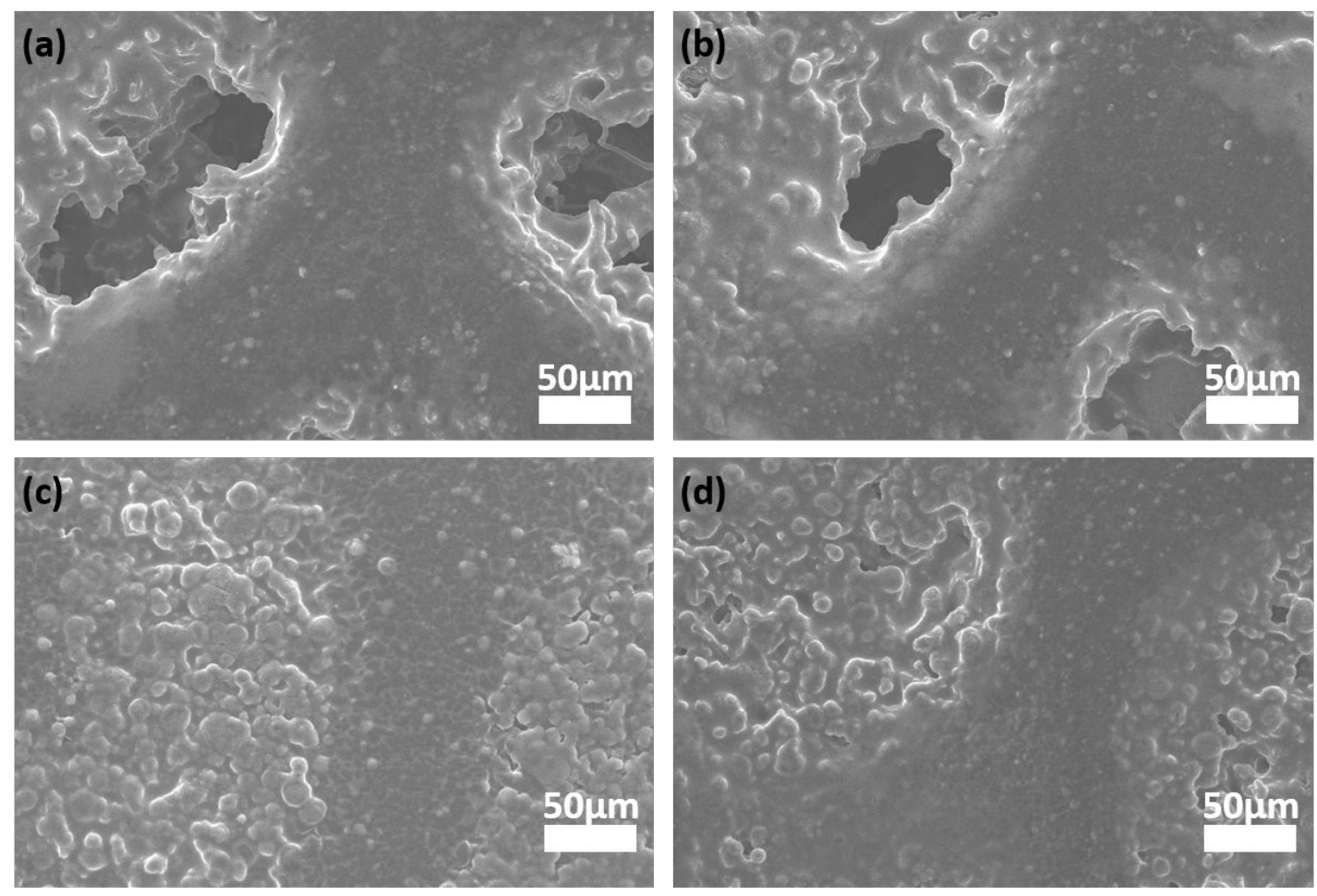

Figure S8 Different amount of Li deposition on $\mathrm{Cu}(\mathrm{f}) @ \mathrm{Sb}$, (a) $6 \mathrm{~mA} \mathrm{~h} \mathrm{~cm}{ }^{-2}$, (b) $8 \mathrm{~mA}$ $\mathrm{h} \mathrm{cm}^{-2}$, (c) $10 \mathrm{~mA} \mathrm{~h} \mathrm{~cm}^{-2}$, and (d) $12 \mathrm{~mA} \mathrm{~h} \mathrm{~cm}^{-2}$.

(a)
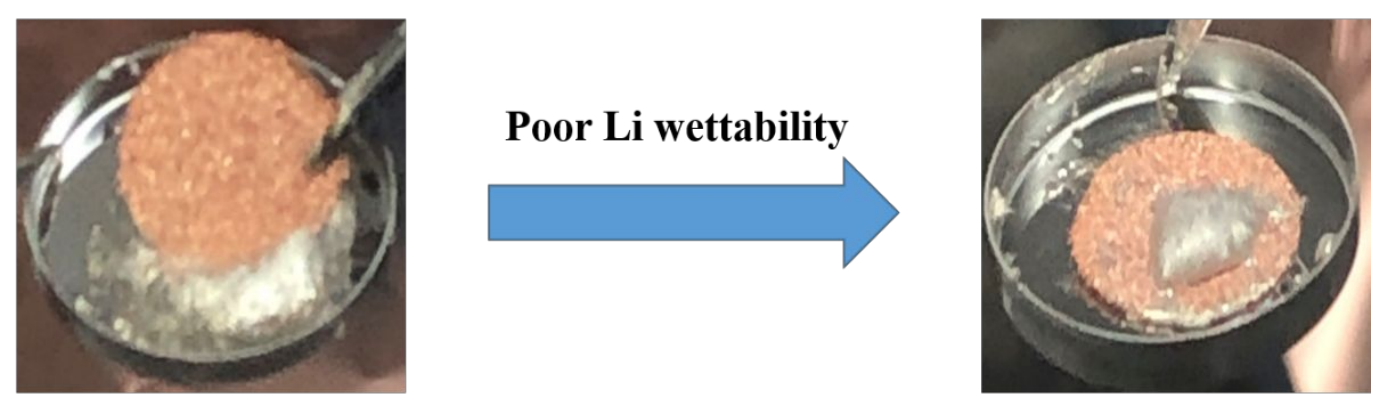

(b)
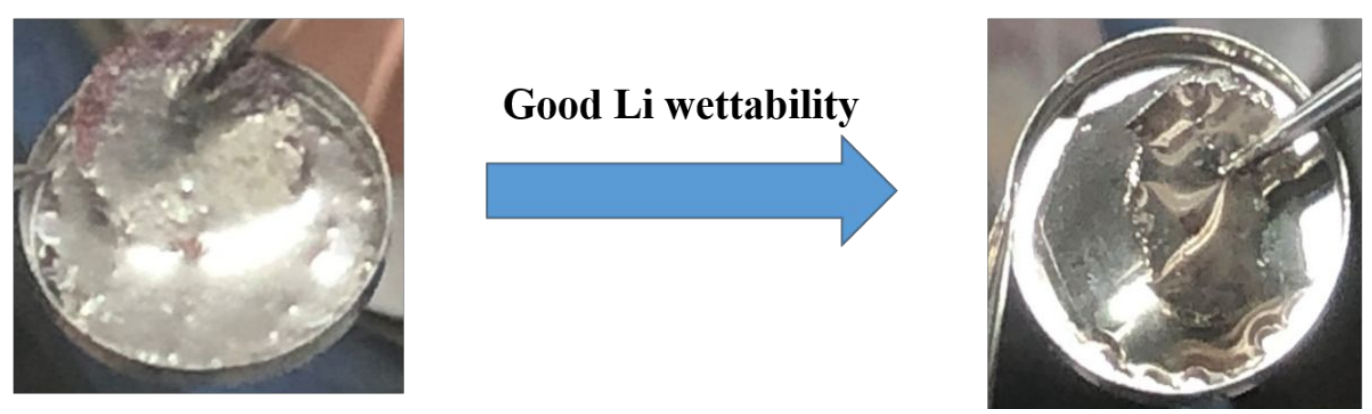

Figure S9 The Li wettability of (a) $\mathrm{Cu}(\mathrm{f})$ and (b) $\mathrm{Cu}(\mathrm{f}) @ \mathrm{Sb}$ at $250^{\circ} \mathrm{C}$. 

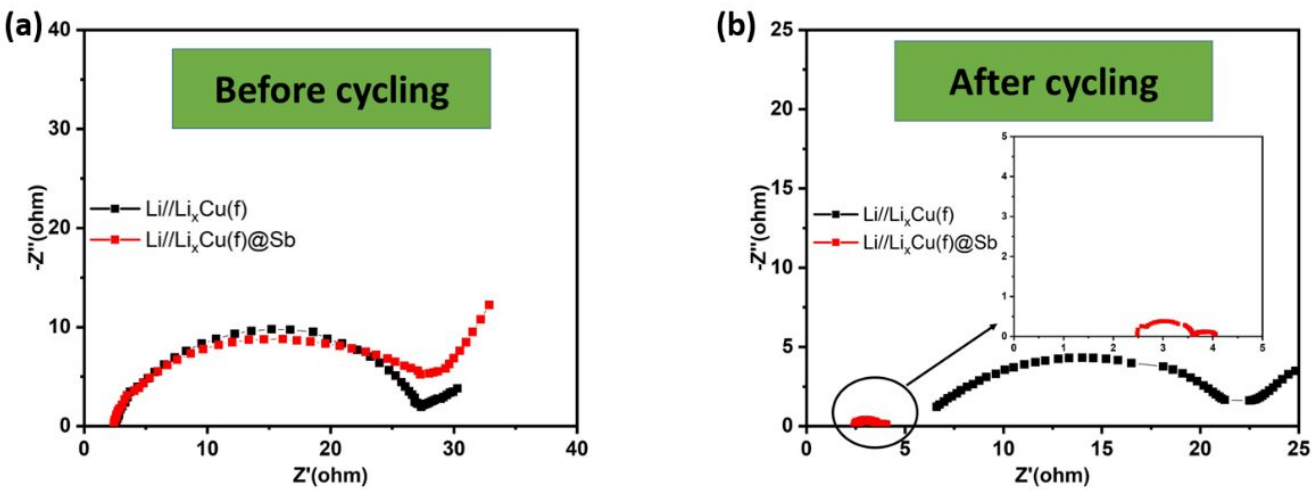

Figure S10 Nyquist plots of both symmetric cells before cycling (a) and after 100 cycles (b).
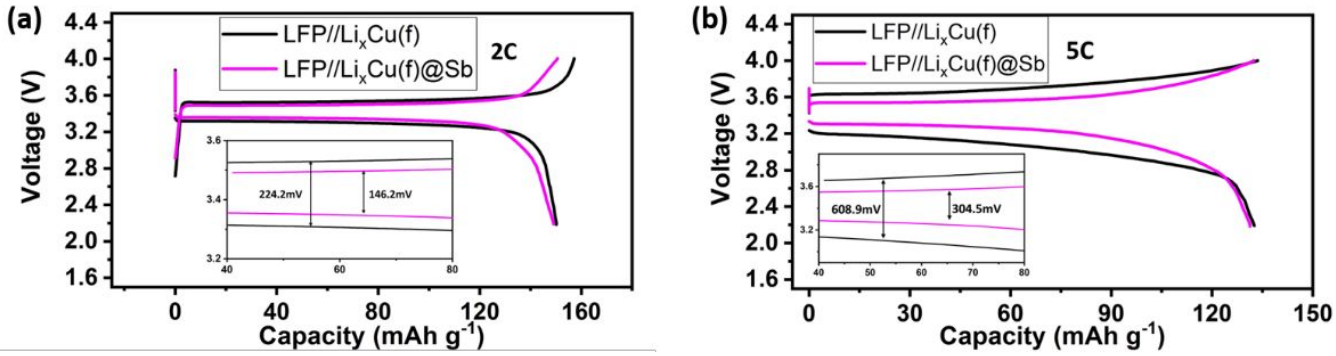

Figure S11 First charge/discharge curves of full cells $\mathrm{LFP} / / \mathrm{Li}_{\mathrm{x}} \mathrm{Cu}(\mathrm{f}) @ \mathrm{Sb}$ and $\mathrm{LFP} / / \mathrm{Li}_{\mathrm{x}} \mathrm{Cu}(\mathrm{f})$ at $2 \mathrm{C}(\mathrm{a})$ and $5 \mathrm{C}(\mathrm{b})$. 